\title{
Kinerja Motor Induksi 1 Fasa Disain 4 Kumparan dengan Kapasitansi Kapasitor Jalan Terkendali
}

\author{
Zuriman Anthony ${ }^{1 *)}$ dan Erhaneli ${ }^{2)}$ \\ ${ }^{1,2)}$ Department of Electrical Engineering, Institut Teknologi Padang, Indonesia \\ Corresponding Email: *) antoslah@gmail.com
}

\begin{abstract}
Single phase induction motor usually has two windings. Because of that, the motor usually operated at lower efficiency than the poly-phase induction motor. A new design had been developed by using poly-phase winding to improve motor efficiency, but characteristic of the current winding at low load condition is not good. So that, this study was aimed to design a 4 phase windings construction of a single phase induction motor that using capacitance control of the run capacitor on auxiliary winding. This design was focused for capacitor-start capacitor-run induction motor that had 4 windings, one winding act as the main winding and the other three windings act as the auxiliary windings. The main and the auxiliary windings current rating of the proposed motor were $2.74 \mathrm{~A}$ and $3.15 \mathrm{~A}$, respectively. The auxiliary winding current of the proposed motor was controlled by the 'Arduino UNO' control system. To get the best control system of the proposed motor, the performances of the proposed motor were compared to the performances of a conventional single-phase induction motor that had the same current rating, stator and rotor construction. The single-phase comparator motor used in this study was a conventional single-phase induction motor of $220 \mathrm{~V}, 50 \mathrm{~Hz}, 1$ HP, 8.3A, 4 poles, 1400 RPM cage rotor. The result showed that the proposed motor to capacitance control in auxiliary winding had better performances than the conventional induction motor.
\end{abstract}

Key words: single phase induction motor, current control system, Arduino UNO, 4 windings construction.

\section{Pendahuluan}

Motor induksi yang umum digunakan saat ini adalah motor induksi 3-fasa dan motor induksi 1-fasa. Motor induksi 3-fasa mempunyai 3 buah kumparan yang identik sama yang secara konstruksi berjarak $120^{\circ}$ listrik, sehingga motor ini mampu bekerja dengan kerapatan arus yang sama untuk kondisi beban yang bervariasi [1]. Arus yang melewati kumparan motor umumnya sama besar jika sumber tegangan 3-fasa yang diberikan ke motor juga seimbang. Lain halnya dengan motor induksi 1-fasa dimana motor ini mempunyai 2 (dua) buah kumparan motor yang disebut dengan kumparan bantu dan kumparan utama dimana kedua kumparan ini mempunyai luas penampang yang berbeda. Karena motor ini mempunyai kumparan dengan luas penampang yang berbeda, maka kerapatan arus yang melewati kumparan motor ini juga tidak sama pada kondisi beban yang bervariasi [1], [2].
Motor induksi 1-fasa bekerja berdasarkan induksi medan magnet stator yang seolah-olah berputar yang sampai ke rotornya. Motor ini umumnya banyak digunakan oleh masyarakat untuk keperluan rumah tangga seperti pompa, kipas angin, dan mesin cuci [1]. Motor ini biasanya menggunakan 2 buah kumparannya saat start dan ada yang menggunakan 1 buah kumparan saja saat jalan. Khusus pada motor 'capasitor startcapasitor run induction motor', maka motor ini menggunakan kedua kumparannya saat start dan saat jalan sehingga motor ini bekerja seperti motor induksi 2fasa [1]. ,Motor jenis ini menggunakan 2 buah kapasitor yang dipasang pada salah satu kumparannya sehingga motor menghasilkan torsi yang besar saat start dan jalan [1], [2]. Penelitian-penelitian dalam usaha meningkatkan kinerja motor ini telah banyak dikembangkan agar motor dapat bekerja lebih baik dan efisien baik dengan cara pengaturan medan magnet, nilai kapasitor, waktu start dan lain sebagainya [3]-[6].

Peningkatan kinerja motor induksi 1-fasa juga telah mulai dilakukan dengan cara mengembangkan disain kumparan motor yang dibuat mirip seperti motor induksi 3-fasa atau 4-fasa [7]-[11]. Penelitian dengan mengembangkan kumparan motor induksi 1-fasa yang dibuat persis sama dengan motor induksi 3-fasa mempunyai kinerja yang lebih baik, dimana motor memeliki faktor daya dan torsi start yang lebih baik dari motor induksi 3-fasa [10], [11]. Tetapi, kemanpuan motor ini berada di bawah motor induksi 3-fasa pembanding dengan rating arus kumparan yang sama. Disamping itu, kerapatan arus yang mengalir pada kumparan motor sangat jauh berbeda pada kondisi beban yang rendah, sehingga tidak disarankan untuk mengoperasikan motor pada kondisi ini dalam waktu yang lama karena dapat memperpendek umur motor. Agar motor induksi 1-fasa dapat bekerja dengan kinerja yang lebih baik, maka sebaiknya kerapatan arus yang mengalir pada kedua kumparan motor induksi 1-fasa harus mendekati sama [12].

Penelitian dengan mengembangkan bentuk kumparan motor induksi 1-fasa yang dibuat persis sama dengan motor induksi 4-fasa (kumparan identik sama) juga telah dikembangkan [8]. Dengan disain ini motor juga mempunyai kinerja yang lebih baik dari motor induksi 1fasa konvensional dengan penggunaan kapasitansi kapasitor yang lebih rendah. Tetapi motor ini juga mempunyai kelemahan dimana torsi mekanik yang dihasilkan motor sedikit lebih rendah dari motor induksi 
1-fasa pembanding dan pada kondisi beban yang rendah, maka kerapatan arus yang mengalir pada kumparan motor jauh berbeda sehingga tidak disarankan untuk beroperasi dengan kondisi ini dalam waktu yang lama.

Kemudian juga telah dikembangkan disain kumparan motor induksi 1-fasa yang dibuat seperti motor induksi 3fasa [9] dan seperti motor induksi 4-fasa [7], tetapi kumparannya tidak identi sama, dimana kumparan bantunya dibuat $15 \%$ lebih besar dari kumparan utamanya. Kinerja motor untuk kedua metode ini lebih baik dari motor induksi pembandingnya, dimana motor memiliki torsi start, torsi mekanik, faktor daya dan efisisensi motor yang lebih besar. Metode ini juga mempunyai permasalahan pada saat beban yang rendah dimana kerapatan arus pada kumparan motor jauh berbeda sehingga tidak disarankan untuk dioperasikan pada kondisi ini dalam waktu yang lama. Oleh karena itu sangat diperlukan sistem kendali untuk mengatur arus kumparan bantu motor ini agar kerapatan arus yang melewati kumparan motor tidak terlalu jauh berbeda sehingga motor dapat bekeraja dengan kinerja yang lebih baik. Salah satu cara yang dapat dilakukan adalah dengan mengatur kapasiansi kapasitor jalan saat terjadi perubahan beban pada motor.

Penelitian yang dilakukan kali ini adalah menganalisa kinerja motor induksi 1-fasa yang dibuat dengan disain 4 kumparan seperti motor induksi 4-fasa, tetapi kumparan bantu motor ini dibuat $15 \%$ lebih besar dari kumparan utamanya. Kapasitansi kapasitor yang dipasang seri dengan kumparan bantu dibuat dapat berubah-ubah yang dikendalikan secara otomatis dengan menggunakan program 'Arduino UNO' agar kerapatan arus pada kumparan bantu dapat dikendalikan tidak terlalu jauh berbeda dengan kerapatan arus pada kumparan utamanya dan arus yang melewati kumparan motor tidak melebihi arus nominal kumparannya sehingga motor dapat beroperasi dengan kinerja yang lebih baik dan aman.

\section{Metodologi}

\section{A. Motor Induksi 1-fasa yang digunakan}

Motor induksi 1-fasa yang digunakan pada penelitian ini didisain mempunyai 4 kumparan, dimana tiga (3) buah kumparan motor dengan nama kumparan U, V, W (disebut kumparan bantu) dibuat lebih besar $15 \%$ dari kumparan X (disebut kumparan utama). Bentuk hubungan kapasitor dengan ke empat kumparan motor ini dipelihatkan pada gambar 1 [7].

Dengan memperhatikan gambar 1 dapat dijelaskan bahwa 3 buah kumparan yang diberi nama U (U1 ke U2), V (V1 ke V2) dan W (W1 ke W2) disebut sebagai kumparan bantu yang terhubung secara seri dengan kapasitor Cr dan Cs. Satu kumparan X (X1 ke X2) yang berdiri sendiri disebut sebagai kumparan utama. Cs dan $\mathrm{Cr}$ secara berturut-turut adalah kapasitor start dan kapasitor jalan yang digunakan pada kumparan bantu. $\mathrm{F}$ dan $\mathrm{N}$ pada gambar 1 adalah simbol dari Fasa (F) dan Netral $(\mathrm{N})$ dari sumber sistem 1-fasa yang dihubungkan ke motor. S1 pada gambar 1 adalah saklar sentrifugal yang digunakan untuk melepas kapasitor Cs setelah kecepatan rotor mencapai kecepatan standarnya. Bentuk distribusi kumparan motor induksi 1-fasa dengan disain 4 kumparan ini secara detail dengan jumlah slot 36 buah pada statornya diperlihatkan pada gambar 2 .

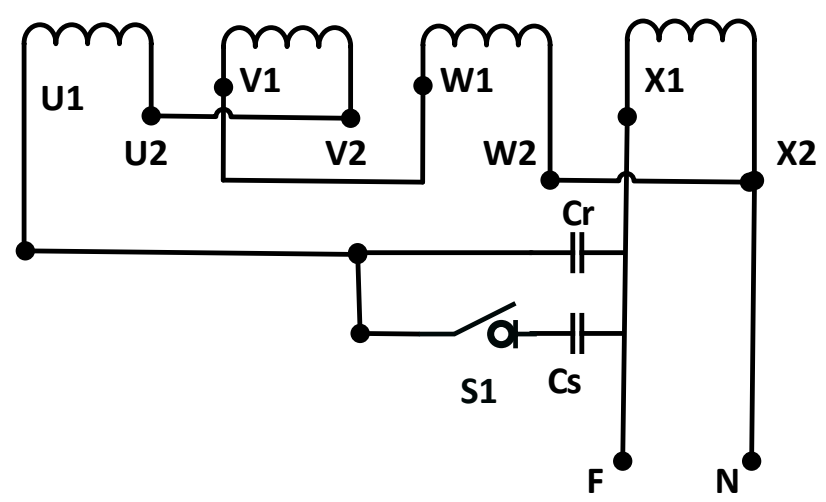

Gambar 1. Bentuk hubungan kumparan bantu dan kumparan utama motor induksi 1-fasa dengan 4 kumparan [7]

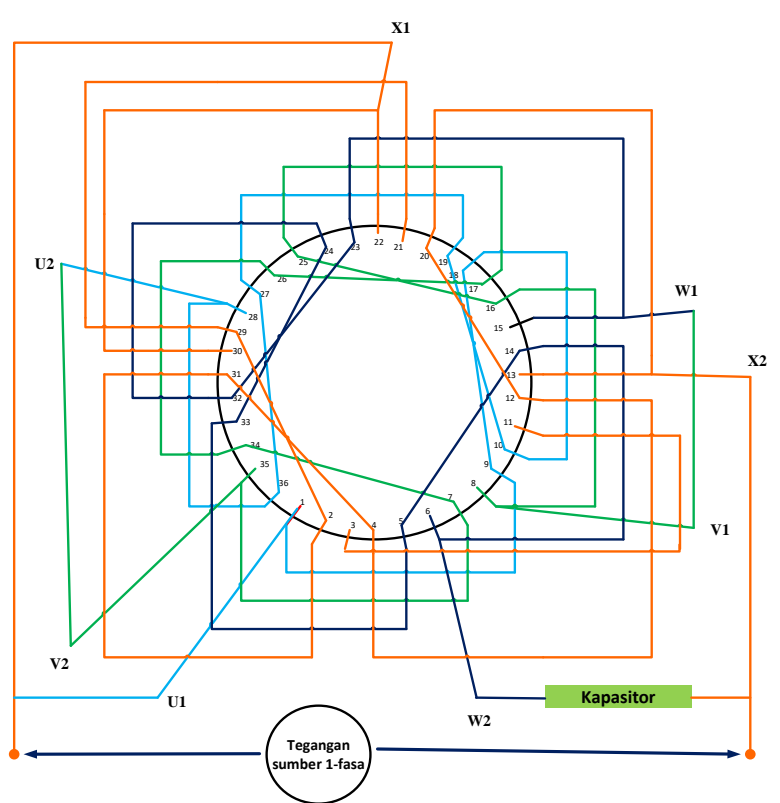

Gambar 2. Bentuk distribusi kumparan motor induksi 1-fasa dengan disain 4 kumparan dengan jumlah slot 36 buah pada stator

Dengan mengacu kepada disain motor induksi pada gambar 1 dan gambar 2, maka dapat dibuatkan rumusrumus yang dapat digunakan untuk menghitung nilai kapasitansi kapasitor sebagai berikut [8].

$$
\begin{aligned}
& C s t=\frac{(0,1757) \cdot I_{N}}{(f) \cdot V_{L N}}(\text { Farad }) \\
& C r=1,25 \frac{I_{p h}}{(\omega) \cdot\left(A_{Z} \cdot V_{L N}\right)} \\
& C s=C s t-C r(\text { Farad })
\end{aligned}
$$


yang mana:

$$
A_{Z}=\frac{N_{U}+N_{V}+N_{W}}{N_{X}}
$$

$I_{N}=$ arus nominal kumparan utama (A)

$V_{L N}=$ sumber tegangan 1 -fasa $(\mathrm{V})$

$f \quad=$ frekuensi sumber $(\mathrm{Hz})$

$\mathrm{A}_{\mathrm{Z}}=$ konstanta Zuriman Anthony

$\mathrm{N}_{\mathrm{U}}=$ jumlah slot yang digunakan kumparan ' $\mathrm{U}$ '

$\mathrm{N}_{\mathrm{V}}=$ jumlah slot yang digunakan kumparan ' $\mathrm{V}$ '

$\mathrm{N}_{\mathrm{W}}=$ jumlah slot yang digunakan kumparan ' $\mathrm{W}$ '

$\mathrm{N}_{\mathrm{X}}=$ jumlah slot yang digunakan kumparan ' $\mathrm{X}$ '

'Cst' adalah kapasitansi kapasitif total yang digunakan pada motor yang terdiri dari ' $\mathrm{Cr}$ ' yang merupakan kapasitansi kapasitor jalan dan 'Cs' yang merupakan kapasitansi kapasitor start.

Motor induksi 1-fasa disain 4 kumparan ini dirancang dengan luas penampang kumparan utama $0,65 \mathrm{~mm}^{2}$ dengan rating arus 2,74 A dan luas penampang kumparan bantu $0,75 \mathrm{~mm}^{2}$ dengan rating arus 3,15 A. Motor induksi 1 -fasa konvensional yang digunakan sebagai pembanding adalah motor induksi 1-fasa dengan data: $220 \mathrm{~V}, 4$ kutup, 8,3 A, $50 \mathrm{~Hz}, 1400$ RPM. Motor ini mempunyai luas penampang kumparan bantu $0,65 \mathrm{~mm}^{2}$ dengan rating arus kumparan 2,74 A dan luas penampang kumparan utama $0,9 \mathrm{~mm}^{2}$ dengan rating arus kumparan 3,8 A dengan kapasitor start ' $\mathrm{Cs}$ ' $=200 \mu \mathrm{F}$ dan kapasitor jalan ' $\mathrm{Cr}$ ' $=30$ $\mu \mathrm{F}$. Motor induksi 1-fasa disain 4 kumparan yang digunakan mempunyai disain rangka stator dan rotor yang sama dengan motor induksi 1-fasa pembanding.

Mengacu ke persamaan (1) sampai dengan (4) dengan sumber tegangan $220 \mathrm{~V}$ dan frekuensi $50 \mathrm{~Hz}$, maka motor induksi 1-fasa disain 4 kumparan ini menggunakan kapasitor start 'Cs' sebesar $20 \mu \mathrm{F}$ dan kapasitor jalan 'Cr' sebesar $25 \mu \mathrm{F}$ yang dibagi 2 menjadi $15 \mu \mathrm{F}$ dan $10 \mu \mathrm{F}$ yang sistem kerjanya dikontrol 'Arduino UNO' dengan menggunakan rele dan kontaktor. Bentuk hubungan 2 buah kapasitor jalan dan 1 buah kapasitor start ini diperlihatkan pada gambar 3 .

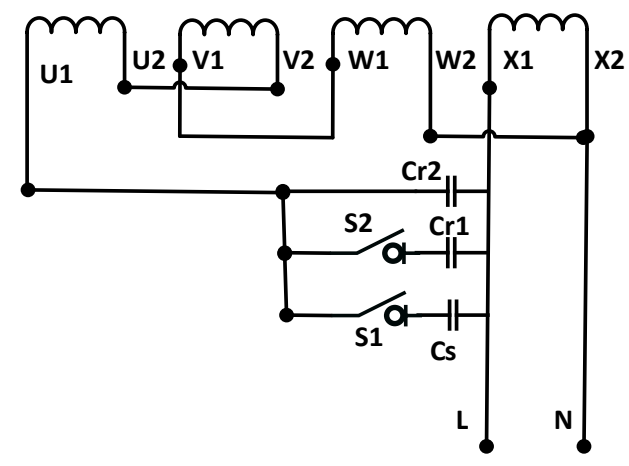

Gambar 3. Bentuk hubungan 2 buah kapasitor jalan dan 1 buah kapasitor start pada kumparan motor induksi 1-fasa dengan disain 4 kumparan

'S1' dan 'S2' pada gambar 3 secara berturut-turut merupakan anak kontak kontaktor 1 (S1) dan kontaktor 2 (S2) yang sumber tenaganya terhubung dengan rele yang dikendalikan dengan menggunakan sistem kendali
'Arduino'. Tujuan dari sistem kendali ini adalah agar arus yang melewati kumparan bantu motor tidak melebihi arus nominalnya dan kerapatan arus yang mengalir pada kumparan motor dapat dikendalikan agar tetap mendekati sama untuk kondisi beban yang berubah ubah. Kapasitor start 'Cs' akan diputus oleh saklar 'S1' bila kecepatan motor telah mencapai $80 \%$ kecepatan standarnya, dengan waktu sekitar 2 detik untuk beban penuh. Sedangkan saklar 'S2' akan aktif (diputuskan) saat motor merasakan beban kurang dari $70 \%$ dan apabila bebanya di atas $70 \%$, maka saklar 'S2' akan tersambung kembali. Keadaan ini dikendalikan oleh sistem kendali 'Arduino UNO' untuk mengontrol aktif dan tidak aktifnya saklar pada rele modul yang terhubung dengan sistem tenaga kontaktor. Bentuk hubungan rele modul dan kapasitor pada terminal kontaktor dari gambar 1, secara detail diperlihatkan pada gambar 4. Pada gambar 4 diperlihatkan kapasitor jalan sebesar $25 \mu \mathrm{F}$ adalah total nilai kapasitansi kapasitor jalan dari hasil perhitungan dari persamaan (2) yang kemudian dapat dibagi menjadi 2 buah yaitu $15 \mu \mathrm{F}$ dan $10 \mu \mathrm{F}$ yang kemudian dirangkai seperti gambar 3 .

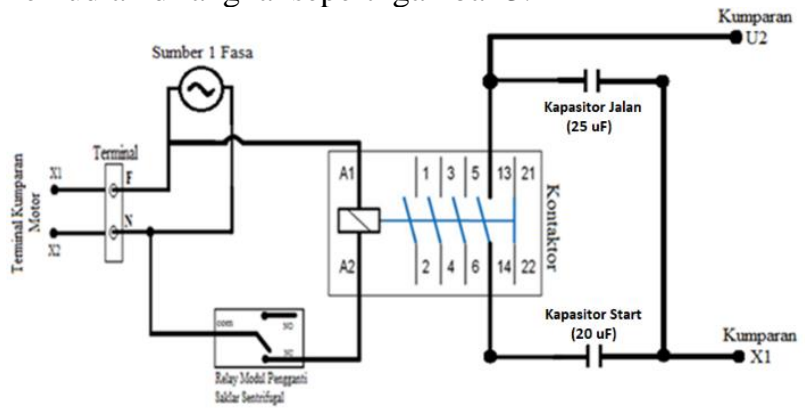

Gambar 4. Bentuk hubungan rele modul dan kapasitor pada terminal kontaktor

\section{B. Sistem Kendali yang Digunakan}

Sistem kendali dibangun dengan menggunakan Arduino UNO beserta perlengkapanya seperti yang diperlihatakan pada gambar 5. Sistem kendali Arduino UNO digunakan untuk memutuskan dan menghubungkan rangkaian kapasitor pada gambar 3 secara otomatis.

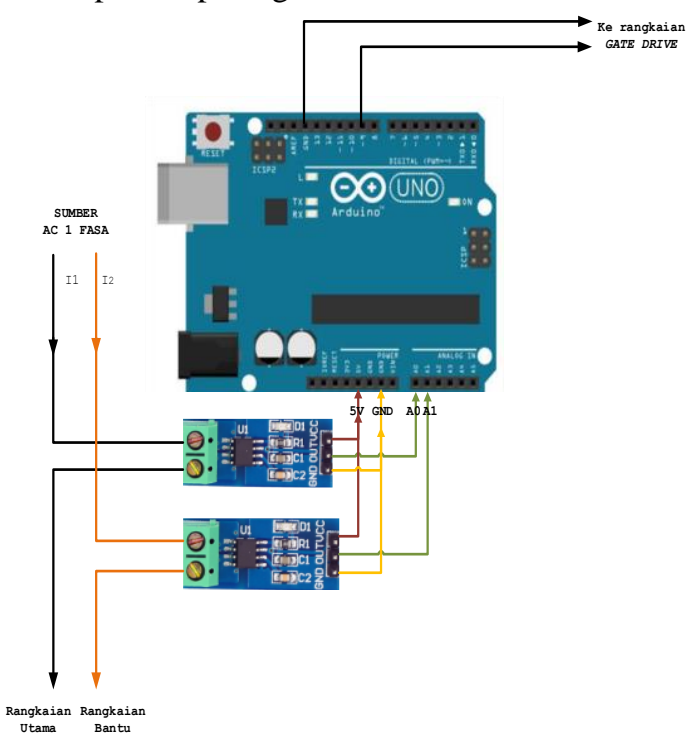

Gambar 5. Arduino UNO beserta rele modul dan arah sambungannya ke rangkaian gate drive, kumparan motor, dan sumber tenaga 1 -fasa 
Arus pada kumparan utama dan kumparan bantu pada gambar 5 digambarkan sebagai I1 dan I2. Aktif dan tidak aktifnya rele yang memutuskan kapasitor pada gambar 3 dikontrol berdasarkan besarnya arus yang melewati kumparan motor yang dikontrol oleh 'Arduino UNO'. Jika arus yang melewati kumparan utama (I1) juga disebut dengan ' $\mathrm{I}_{\mathrm{A}}$ ' dan arus yang melewati kumparan bantu (I2) juga disebut dengan ' $\mathrm{I}_{\mathrm{B}}$ ' pada motor induksi 1-fasa, maka bentuk hubungan vektor kedua arus ini diperlihatkan seperti gambar 6 [12] dengan asumsi faktor daya motor tertinggal.

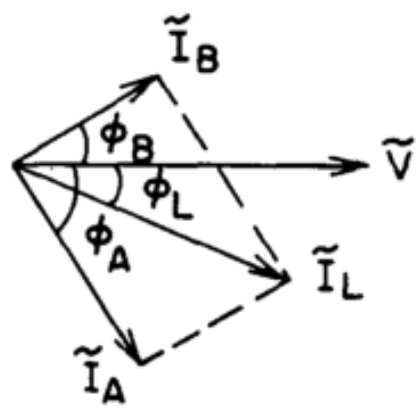

Gambar 6. Hubungan arus kumparan utama $\left(\mathrm{I}_{\mathrm{A}}\right)$ dan arus kumparan bantu $\left(\mathrm{I}_{\mathrm{B}}\right)$ secara vektor [12]

Dengan memperhatikan gambar 6 dapat dijelaskan bahwa $\mathrm{I}_{\mathrm{L}}$ adalah merupakan arus total yang masuk ke kumparan motor induksi 1-fasa sedangkan $\mathrm{V}$ adalah tegangan sumber 1-fasa yang diberikan kepada motor. Dengan memperhatikan gambar 6 juga terlihat bahwa vektor arus ' $I_{L}$ ' pada gambar berada di bawah vektor sumber tegangan ' $\mathrm{V}$ ' sehingga motor pada kondisi ini disebut mempunyai faktor daya tertinggal. Sedangkan bila vektor arus ' $\mathrm{L}_{\mathrm{L}}$ ' berada di atas ' $\mathrm{V}$ ' maka faktor daya motor disebut mendahului [1]. Bentuk hubungan arus pada kumparan motor ini secara vektor dapat dibuatkan sebagai berikut.

$$
I_{L}=\overrightarrow{I_{A}}+\overrightarrow{I_{B}}
$$

Kemudian, kerapatan arus yang melewati masingmasing kumparan dapat dihitung sebagai berikut [12].

$$
\begin{gathered}
J A=\frac{I_{A}}{A_{A}} \\
J B=\frac{I_{B}}{A_{B}}
\end{gathered}
$$

yang mana:

JA = kerapatan arus pada kumparan utama

JB = kerapatan arus pada kumparan bantu

$\mathrm{I}_{\mathrm{A}} \quad$ = Arus yang melewati kumparan utama

$\mathrm{I}_{\mathrm{B}} \quad$ = Arus yang melewati kumparan bantu

$\mathrm{A}_{\mathrm{A}}=$ luas penampang kumparan utama

$\mathrm{A}_{\mathrm{B}} \quad$ = luas penampang kumparan bantu

\section{Hasil dan Pembahasan}

Dari hasil penelitian yang telah dilakukan dengan menguji langsung motor induksi 1-fasa disain 4 kumparan dan motor induksi 1-fasa konvensional di Laboratorium, maka diperoleh hasil bentuk Kharakteristik arus kumparan bantu motor 'Ib' terhadap perubahan daya keluaran motor seperti yang diperlihatkan pada gambar 7 . Kemudian juga diperlihatkan bentuk Kharakteristik efisiensi motor terhadap perubahan daya keluaran motor seperti yang diperlihatkan pada gambar 8. Hasil perbandingan kinerja motor induksi 1-fasa disain 4 kumparan terhadap motor induksi 1-fasa konvensional diperlihatkan pada tabel 1 .

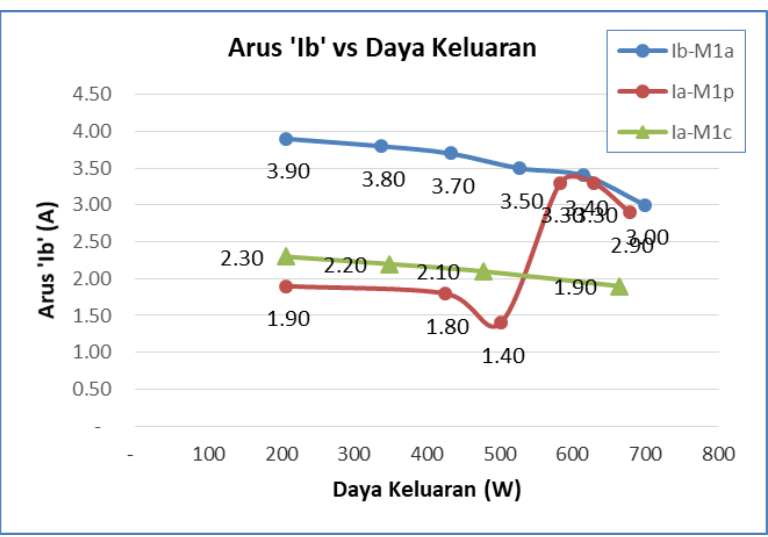

Gambar 7. Kharakteristik arus kumparan bantu motor ' $\mathrm{Ib}$ ' terhadap perubahan daya keluaran motor

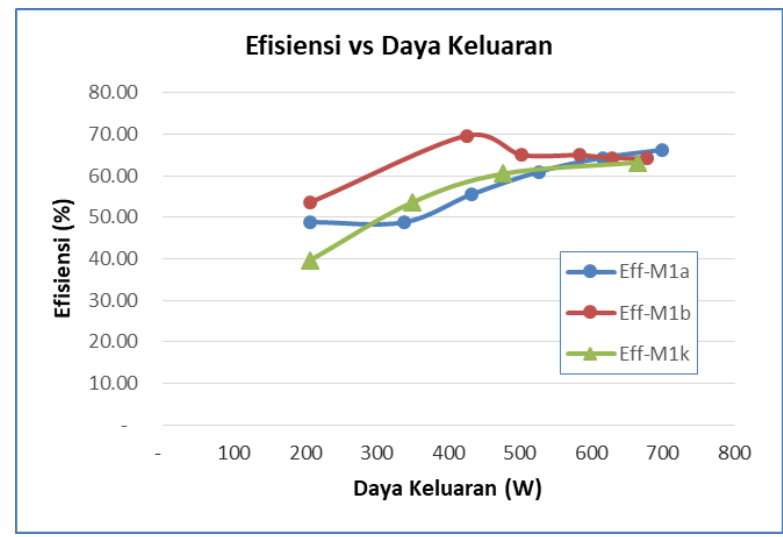

Gambar 8. Kharakteristik efisiensi motor terhadap perubahan daya keluaran motor

Dari gambar 7 dapat dijelaskan bahwa 'Ib-M1a' adalah arus kumparan bantu pada motor induksi 1-fasa disain 4 kumparan yang menggunakan saklar sentrifugal tanpa kendali kapasitansi kapasitor, 'Ib-M1b' adalah arus kumparan bantu pada motor induksi 1-fasa disain 4 kumparan yang tidak menggunakan saklar sentrifugal tetapi pemutusan hubungan kapasitor dikontrol secara otomatis oleh 'Arduino UNO', dan Ib-M1k' adalah arus kumparan bantu pada motor induksi 1-fasa konvensional yang menggunakan saklar sentrifugal.

Dari gambar 7 terlihat bahwa arus kumparan bantu pada motor induksi 1-fasa disain 4 kumparan dengan 
pengendalian kapasitansi kapasitor pada kumparan bantu (MIb) mempunyai kharakteristik yang lebih baik, dimana untuk beban yang rendah arusnya juga rendah dan untuk beban yang tinggi arusnya juga tinggi tetapi masih dibawah stardar arus nominalnya. Dari data hasil kerapatan arus pada kumparan motor, ternyata kerapatan arus pada kumparan motor disain 'M1b' hampir mendekati sama sehingga motor dapat beroperasi dengan kinerja yang lebih baik dengan suara yang lebih halus dari 2 metode yang lainnya (metode M1a dan M1k). Dengan kondisi ini, maka motor akan dapat beroperasi dengan kinerja yang baik dengan kondisi beban yang berubah ubah.

Bila diperhatikan hasil grafik pada gambar 8 terlihat bahwa saat beban rendah, ternyata motor induksi 1-fasa disain 4 kumparan dengan pengendali kapasitansi kapasitor ini menghasilkan efisiensi yang lebih besar (EffM1b) karena arus yang melewati kumparan bantu dapat dikontrol menjadi lebih rendah sehingga rugi-rugi pada kumparan motor menjadi lebih kecil. Dari gambar 8 terlihat bahwa Efisiensi motor ini (Eff-M1b) pada beban yang rendah lebih baik dari motor induksi 1-fasa konvensional (Eff-M1k) dan motor induksi 1-fasa disain 4 kumparan dengan kapasitansi kapasitornya tidak dikendalikan (Eff-M1a).

Tabel 1. Perbandingan kinerja motor induksi 1-fasa disain 4 kumparan terhadap motor induksi 1-fasa konvensional

\begin{tabular}{|c|c|c|c|c|}
\hline No. & Jenis Data & M1b & M1a & M1k \\
\hline 1. & $\begin{array}{l}\text { Daya keluaran } \\
\text { (W) }\end{array}$ & 678.44 & 699,08 & 664.36 \\
\hline 2. & Faktor daya & 0.977 & 0,961 & 0.978 \\
\hline 3. & $\begin{array}{l}\text { Arus } \\
\text { kumparan } \\
\text { bantu (A) } \\
\end{array}$ & 2.9 & 3 & 1.9 \\
\hline 4. & $\begin{array}{l}\text { Arus } \\
\text { kumparan } \\
\text { utama (A) } \\
\end{array}$ & 2.6 & 2 & 4.3 \\
\hline 5. & $\begin{array}{l}\text { Kerapatan arus } \\
\text { pada kumparan } \\
\text { bantu }\left(\mathrm{A} / \mathrm{mm}^{2}\right)\end{array}$ & 3,86 & 4,62 & 2,92 \\
\hline 6. & $\begin{array}{l}\text { Kerapatan arus } \\
\text { pada kumparan } \\
\text { utama } \\
\left(\mathrm{A} / \mathrm{mm}^{2}\right)\end{array}$ & 4,00 & 3,08 & 4,70 \\
\hline 7. & Cs $(\mu \mathrm{F})$ & 20 & 20 & 200 \\
\hline 8. & $\mathrm{Cr}(\mu \mathrm{F})$ & $15+10$ & 25 & 30 \\
\hline 9. & $\begin{array}{l}\text { Kecepatan } \\
\text { rotor (RPM) }\end{array}$ & 1403 & 1402 & 1394 \\
\hline
\end{tabular}

Keterangan tabel:

$\mathrm{M} 1 \mathrm{k}=$ motor induksi 1-fasa konvensional

$\mathrm{M} 1 \mathrm{a}=$ motor induksi 1 -fasa disain 4 kumparan tanpa kendali kapasitansi kapasitor

$\mathrm{M} 1 \mathrm{~b}=$ motor induksi 1-fasa disain 4 kumparan dengan arus kumparan bantu terkendali dengan cara mengendalikan kapasitansi kapasitor jalan.
Dengan memperhatikan tabel 1 juga terlihat bahwa motor induksi 1-fasa disain 4 kumparan secara umum mempunyai kinerja yang lebih baik dan lebih efisien dari motor induksi 1-fasa konvensional, dimana nilai kapasitansi kapasitor yang digunakan motor ini lebih rendah dan dengan daya keluaran motor serta kecepatan rotor yang lebih tinggi dari motor induksi 1-fasa konvensional. Dari tabel 1 ini terlihat bahwa untuk kinerja motor yang terbaik adalah pada motor induksi 1-fasa disain 4 kumparan dengan kapasitansi kapasitor jalan yang terkendali oleh sistem kendali 'Arduino UNO'. Disain terbaik dari pengendali kapasitansi kapasitor ini adalah dengan menggunakan kapasitansi kapasitor jalan sebesar $60 \%$ dari rumus yang telah diberikan pada persamaan (2) dan (4) bila motor diberi beban kurang dari $70 \%$, dan saat beban di atas $70 \%$ maka nilai kapasitansi kapasitor jalan diset $100 \%$ yang secara otomatis dikendalikan oleh sistem kendali 'Arduino UNO'.

\section{KESIMPULAN}

Secara umum, motor induksi 1-fasa disain 4 kumparan dapat bekerja dengan kinerja yang lebih baik dari motor induksi 1-fasa konvensional. Tetapi, bila arus kumparan bantu dikendalikan dengan cara mengendalikan nilai kapasitansi kapasitor jalan yang dipasang pada kumparan bantu, maka motor akan bekerja dengan kinerja yang lebih baik, dimana motor dapat bekerja dengan efisiensi dan kecepatan rotor yang lebih besar dan dengan arus kumparan yang lebih rendah serta nilai kapasitansi kapasitor yang lebih rendah dari motor induksi konvensional. Disain kendali kapasitansi kapasitor tebaik untuk motor ini adalah dengan menggunakan kapasitansi kapasitor jalan sebesar $60 \%$ bila motor diberi beban kurang dari $70 \%$, dan saat beban di atas $70 \%$ maka nilai kapasitansi kapasitor jalan diset $100 \%$ dari standar rumus yang telah diberikan.

\section{UCAPAN TERIMA KASIH}

Kami mengucapkan banyak terimakasih atas bantuan dari semua pihak yang telah banyak membantu sehingga penelitian ini dapat berjalan dengan baik. Kami juga tidak lupa mengucapkan banyak terimakasih kepada 'LLDIKTI X' serta 'Direktorat Jenderal Pendidikan Tinggi, Riset dan Teknologi Republik Indonesian' yang telah mendanai penelitian ini, dengan kontrak penelitian Nomor: 330/27.O10.5/PN/II/2019. 


\section{Daftar Pustaka}

[1] P. C. Sen, Principles of Electrical Machines and Power Electronics, 2nd ed. New York: John Wiley \& Sons, 1997.

[2] S. J. Chapman, Elecrical Machinery Fundamentals, 4th ed. New York: McGraw-Hill, 2005.

[3] A. Nied and J. De Oliveira, "Improving Washing Machine Performance Using Single-Phase Induction Motor Field-Oriented Control," pp. 2917-2922, 2013.

[4] H. M. B. Metwally, "New method for speed control of single phase induction motor with improved motor performance," Energy Convers. Manag., vol. 42, no. 8, pp. 941-950, 2001.

[5] S. Sobhani, H. Yaghobi, and M. Samakoosh, "Optimize efficiency and torque in the single-phase induction motor by adjusting the design parameters," 12th Int. Conf. Environ. Electr. Eng. EEEIC 2013, pp. 237-241, 2013.

[6] T. Liu, M. Lin, and H. Wu, "A single phase induction motor drive with improved performance," vol. 47, pp. 29-38, 1998.

[7] Z. Anthony and E. Erhaneli, "Desain Lilitan Motor Induksi 1-Fasa dengan 4 Kumparan yang Tidak Identik Sama ( Studi kasus: daya keluaran dan efisiensi motor)," EECCIS, vol. 12, no. 2, pp. 89-92, 2018.

[8] Z. Anthony, E. Erhaneli, and Z. Zulkarnaini, "Windings Design for Single-phase Induction Motors Base on 4phase Induction Motor ( Case study : identical windings design )," in ICTIS 2018, 2018, vol. 01023, pp. 1-4.

[9] Z. Anthony and E. Erhaneli, “A New Windings Design of 24 Slot Capacitor-Start Capacitor-Run Induction Motor," IJECE, vol. 8, no. 5, pp. 3463-3470, 2018.

[10] Z. Anthony and E. Erhaneli, "Disain Baru Bentuk Lilitan Kumparan Motor Induksi 1-fasa Berbasis Bentuk Lilitan Motor Induksi 3-fasa," in PIMIMD-4 2017, pp. 245249, 2017.

[11] Z. Anthony and E. Erhaneli, "A New Winding Design for Single Phase Induction Motor," in ICo-ASNITech 2017, pp. 153-160, October, 2017.

[12] J. C. White and H. Huang, "Optimal Placement of The Run Capacitor in Single-Phase Induction Motor Designs", IEEE Trans. Energy Convers., vol 3, no. 3, pp. 647-652, 1988. 